\title{
EFEITOS DO ALCOOLISMO CRÔNICO E DA DESINTOXICAÇÃO ALCÓOLICA SOBRE A GLÂNDULA SUBMANDIBULAR DE RATOS. ESTUDO MORFOMÉTRICO
}

\author{
EFFECTS OF CHRONIC ALCOHOLISM AND ALCOHOLIC DETOXICATION ON \\ RAT SUBMANDIBULAR GLANDS. MORPHOMETRIC STUDY
}

\author{
Simone Eloiza Sita FAUSTINO \\ Cirurgiã-dentista graduada pela Faculdade de Odontologia de Bauru da Universidade de São Paulo.

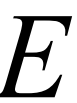
ste estudo consiste de uma análise morfométrica de diversas estruturas parenquimatosas da glândula submandibular de ratos submetidos ao alcoolismo crônico experimental e de ratos recuperados após 30 dias de desintoxicação. Foram utilizados 3 grupos (5 animais por grupo): Controle, Alcoolizado e Desintoxicado. O fato do álcool atuar nos tecidos corporais, leva-nos a acreditar que possam ocorrer alterações na morfologia da glândula submandibular de ratos submetidos ao alcoolismo crônico. De fato, após os processos de alcoolização e desintoxicação há ocorrência de diferenças estatisticamente significantes quando confrontamos os 3 grupos entre si (dois a dois) no que se refere à massa corpórea dos animais (g) e da glândula submandibular (mg), ocorrendo, normalmente, uma redução tanto do grupo alcoolizado quanto do grupo desintoxicado em relação ao grupo controle e um significante aumento das massas corpórea e glandular do grupo desintoxicado em relação ao grupo alcoolizado. Quanto ao volume absoluto das diversas estruturas glandulares analisadas constatou-se diferenças estatisticamente significantes nos compartimentos acinar e do ducto granuloso, onde os grupos alcoolizado e desintoxicado apresentaram menor volume absoluto em relação ao grupo controle. Quanto aos outros parâmetros estereológicos estudados não houve diferenças estatisticamente significantes entre os grupos e entre as diversas estruturas glandulares analisadas.
\end{abstract}

UNITERMOS: Alcoolismo; Desintoxicação; Glândula submandibular; Ratos.

\section{INTRODUÇÃO}

O alcoolismo se destaca hoje como um dos mais graves problemas de saúde pública, devido às complicações sobrevindas no plano somático e psíquico além da profunda repercussão no meio social.

É do conhecimento de todos que o alcoolismo excessivo e prolongado causa uma multiplicidade de anormalidades clínicas, bioquímicas e fisiológicas. Quanto aos órgãos do trato gastrointestinal os efeitos do álcool manifestam-se de modo evidente, talvez por este ser o primeiro segmento corpóreo a receber elevadas concentrações de etanol; essa substância difunde-se através da mucosa do trato gastrointestinal, afetando inclusive as glândulas salivares (Banderas, et $\left.a_{1}{ }^{2}, 1992\right)$. Sabe-se também que a ingestão de álcool provoca alterações na saliva causando diminuição no fluxo salivar e modificações na sua consistência, tornando-a mais viscosa. Dessas mudanças podem advir alterações nas glândulas salivares, consequiência direta ou indireta da ação do álcool. A glândula alterada pode gerar mudanças morfológicas tanto na porção condutora como na porção secretora e essas, por sua vez, promoverem alterações no fluxo salivar que, possivelmente, provoquem modificações morfológicas no parênquima glandular, ou vice-versa.

As glândulas salivares são classificadas em dois grupos: maiores e menores. As glândulas salivares 
menores possuem fluxo salivar contínuo enquanto nas maiores a secreção é controlada principalmente pelo Sistema Nervoso Autônomo, portanto, mais suscetíveis a alterações pelo consumo crônico de álcool. Sendo a glândula submandibular a responsável por cerca de $60 \%$ a $70 \%$ do total da saliva, buscou-se, neste trabalho, a realização de um estudo morfométrico de diversas estruturas parenquimatosas da glândula submandibular de ratos submetidos ao alcoolismo crônico experimental e de ratos recuperados após 30 dias de desintoxicação, com a finalidade de se detectar possíveis alterações relacionadas ao consumo de álcool.

\section{MATERIAL E MÉTODOS}

\section{Procedimentos histológicos}

Foram utilizados 15 ratos machos ( $\underline{\text { Rattus }}$ novergicus) da linhagem Wistar, com 90 dias de idade e com massa corporal entre 250 e 300 gramas. Os animais foram divididos em três grupos:

I) Grupo Controle: recebeu apenas água filtrada como dieta líquida;

II) Grupo Alcoolizado: seguiu o modelo de alcoolismo crônico determinado de "semi-voluntário", sendo o álcool o único alimento líquido disponível ao animal. Primeiramente os ratos passaram por um breve período de adaptação gradativo ao álcool (metodologia segundo Cagnon $\left.{ }^{3}, 1993\right)$, recebendo, por uma semana, dieta líquida à base de álcool etílico a 5\%, da segunda à quinta semana álcool etílico a $10 \%$ e na sexta semana álcool etílico a $20 \%$, permanecendo com essa dieta até a vigésima semana;

III) Grupo Desintoxicado: passou pelo mesmo processo do Grupo Alcoolizado, no entanto, ao invés de serem sacrificados ao final da vigésima semana, os animais passaram por um breve período de desadaptação gradativa ao álcool, recebendo uma dieta líquida à base de álcool etílico a $10 \%$ na vigésima primeira semana, a 5\% na vigésima Segunda semana e uma dieta líquida à base de água filtrada até a vigésima Quinta semana, sendo, após esse período, considerados como desintoxicados.

Ao final de cada período os animais foram sacrificados por inalação de éter etílico. Determinouse a massa corporal ( $\mathrm{g}$ ) de cada animal e a massa das glândulas submandibulares (mg). Em seguida, o material foi fixado em solução de formol a $10 \%$ em tampão fosfato por 24 horas, em temperatura ambiente, passando a seguir por processamentos histológicos estandardizados de desidratação e diafanização em xilol e inclusão em resina Paraplast. Foram obtidos cortes semi-seriados de $6 \mu \mathrm{m}$ de espessura em micrótomo Multicut-Leica-Jung e corados pela técnica de Hematoxilina/Eosina (HE).

\section{Estimativa do volume processado da glândula submandibular (Tabela 1)}

O volume processado da glândula submandibular de cada animal foi calculado pela seguinte relação: $\mathbf{V p}=\mathbf{m} . \mathbf{S f} / \mathbf{d}$, onde: $\mathrm{Vp}=$ volume processado em $\mathrm{mm}^{3} ; \mathrm{m}=$ massa fresca da glândula em $\mathrm{mg} ; \mathrm{Sf}=$ fator de retração médio $(\mathrm{Sf}=0,47) ; \mathrm{d}=$ densidade média da glândula $\left(\mathrm{d}=1,072 \mathrm{mg} / \mathrm{mm}^{3}\right)$. A densidade foi determinada pelo método de Scherle ${ }^{13}$ (1970), segundo indicações de Pardini, Taga ${ }^{12}$ (1986) e a retração provocada na glândula, pelos procedimentos histológicos, pelo método apresentado por Taga, Sesso $^{6}$ (1978).

\section{Estimativa da densidade de volume (vvi) e do volume absoluto (vti) de cada estrutura glandular (i) (Tabela 2)}

A densidade de volume em \% (Vvi) das células acinosas, ductos e estroma foi determinada com a utilização de uma grade de integração II Zeiss exibindo

TABELA 1-Massa corporal (g), massa glandular (mg) e volume glandular $\left(\mathrm{mm}^{3}\right)$ dos Grupos Controle, Alcoolizado I, Alcoolizado II e Desintoxicado

( \pm ) desvio padrão

\begin{tabular}{|c|c|c|c|c|c|c|c|c|}
\hline \multirow{2}{*}{$\begin{array}{l}\text { Massa Corporal (g) } \\
\text { Início - 23/08/99 }\end{array}$} & \multicolumn{2}{|c|}{ CONTROLE } & \multicolumn{2}{|c|}{ ALCOOLIZADO I } & \multicolumn{2}{|c|}{ ALCOOLIZADO II } & \multicolumn{2}{|c|}{ DESINTOXIDADO } \\
\hline & 272,2 & $\pm 8,90$ & 263,4 & $\pm 6,74$ & 250,6 & $\pm 12,78$ & - & - \\
\hline Fase I - 17/01/00 & 398,6 & $\pm 3,99$ & 297,5 & $\pm 7,09$ & 289,5 & $\pm 4,08$ & - & - \\
\hline Fase II - 23/02/00 & - & - & - & - & - & - & 384,3 & $\pm 12,24$ \\
\hline Massa Glandular (mg) & \multicolumn{2}{|c|}{$590,49 \pm 17,877$} & \multicolumn{2}{|c|}{$352,02 \pm 17,127$} & - & - & 449,82 & $\pm 21,631$ \\
\hline Volume Glandular $\left(\mathrm{mm}^{3}\right)$ & \multicolumn{2}{|c|}{$258,89 \pm 7,838$} & \multicolumn{2}{|c|}{$154,34 \pm 7,509$} & - & - & 197,22 & $\pm 9,484$ \\
\hline
\end{tabular}


100 pontos e 10 linhas paralelas, num microscópio contendo uma ocular kpl 8X e uma objetiva de imersão de 100X. Em 50 campos histológicos selecionados por amostragem sistemática para cada animal Weibel ${ }^{18}$ (1969), anotamos o número de pontos sobre cada estrutura glandular $(\mathrm{Pi})$ e sobre a glândula $(\mathrm{P})$. A densidade de volume foi então calculada pela seguinte relação:

$$
\mathbf{V v i}=\mathbf{P i} / \mathbf{P}
$$

Conhecendo-se o volume submandibular processado (Vp) e a densidade de volume de cada estrutura (Vvi), calculou-se o volume absoluto em $\mathrm{mm}^{3}$ (Vti) de cada componente glandular, pela relação:

$$
\mathbf{V t i}=\mathbf{V v i} \text {. Vp }
$$

$\mathrm{O}$ coeficiente de variação ( $\mathrm{e}=$ erro) presente na determinação da densidade de volume (Vvi), foi calculado usando a fórmula de Schaefer:

$$
\mathbf{e}=\mathbf{v}(1-\text { Vvi }) / \mathbf{v}(\text { P.Vvi })
$$

\section{Estimativa do volume nuclear (vn) e citoplasmático (vcit) das células acinosas e células do ducto granuloso (Tabela 2)}

O volume absoluto dos núcleos das células acinosas, considerados esféricos, foi calculado pela fórmula geométrica da esfera:

Vnac $=4 / 3$. ð. $R^{3}$, onde: $r=$ raio médio do núcleo.

$\mathrm{O}$ raio médio foi calculado a partir de medidas ortogonais dos diâmetros de 50 núcleos por animal, através de uma ocular micrométrica 10X Olympus de filamento deslocável, tipo Ramsden, e objetiva de imersão 100X Zeiss. De posse das medidas ortogonais

TABELA 2- Resultados morfométricos da glândula submandibular de ratos submetidos ao alcoolismo experimental e

\begin{tabular}{|c|c|c|c|c|c|c|}
\hline \multirow{2}{*}{$\begin{array}{l}\text { Densidade De Volume (\%) } \\
\text { Ácino }\end{array}$} & \multicolumn{2}{|c|}{ CONTROLE } & \multicolumn{2}{|c|}{ ALCOOLIZADO } & \multicolumn{2}{|c|}{ DESINTOXICADO } \\
\hline & 51,58 & $\pm 3,36$ & 51,49 & $\pm 1,89$ & 51,74 & $\pm 0,92$ \\
\hline Ducto Granuloso & 24,93 & $\pm 1,06$ & 21,88 & $\pm 1,57$ & 25,86 & $\pm 1,78$ \\
\hline Ducto Estriado & 2,54 & $\pm 0,38$ & 2,27 & $\pm 0,18$ & 2,69 & $\pm 0,56$ \\
\hline Ducto Excretor & 2,06 & $\pm 1,26$ & 1,65 & $\pm 0,75$ & 1,18 & $\pm 0,52$ \\
\hline Outras Estruturas & 18,88 & $\pm 2,00$ & 22,71 & $\pm 1,31$ & 18,54 & $\pm 1,23$ \\
\hline \multicolumn{7}{|l|}{ Volume Absoluto $\left(\mathrm{mm}^{3}\right)$} \\
\hline Ácino & 132,82 & $\pm 6,09$ & 79,67 & $\pm 5,69$ & 102,07 & $\pm 5,36$ \\
\hline Ducto Granuloso & 64,62 & $\pm 3,61$ & 33,43 & $\pm 1,74$ & 50,74 & $\pm 3,57$ \\
\hline Ducto Estriado & 6,52 & $\pm 0,93$ & 3,54 & $\pm 0,42$ & 5,44 & $\pm 1,25$ \\
\hline Ducto Excretor & 5,48 & $\pm 3,32$ & 2,58 & $\pm 1,19$ & 2,17 & $\pm 0,92$ \\
\hline Outras Estruturas & 49,45 & $\pm 6,40$ & 35,11 & $\pm 3,03$ & 36,80 & $\pm 3,82$ \\
\hline \multicolumn{7}{|c|}{ Densidade de Volume Corrigida (\%) } \\
\hline Núcleo do Ácino & 1,76 & $\pm 0,11$ & 1,79 & $\pm 0,06$ & 2,21 & $\pm 0,07$ \\
\hline Citoplasma do Ácino & 98,24 & $\pm 0,11$ & 98,21 & $\pm 0,06$ & 97,79 & $\pm 0,07$ \\
\hline Núcleo do Ducto Granuloso & 1,38 & $\pm 0,14$ & 0,84 & $\pm 0,12$ & 1,13 & $\pm 0,08$ \\
\hline Citoplasma do Ducto Granuloso & 98,62 & $\pm 0,14$ & 99,16 & $\pm 0,12$ & 98,88 & $\pm 0,08$ \\
\hline \multicolumn{7}{|l|}{ Volume Absoluto $\left(\mu \mathrm{m}^{3}\right)$} \\
\hline Núcleo do Ácino & 127,72 & $\pm 14,60$ & 93,35 & $\pm 5,91$ & 124,42 & $\pm 12,48$ \\
\hline Citoplasma do Ácino & 7336,04 & $\pm 1080,51$ & 5098,00 & $\pm 214,27$ & 5516,01 & $\pm 547,27$ \\
\hline Célula do Ácino & 7463,76 & & 5191,35 & & 5640,43 & \\
\hline Núcleo do Ducto Granuloso & 173,66 & $\pm 8,37$ & 125,97 & $\pm 14,84$ & 134,51 & $\pm 2,60$ \\
\hline Citoplasma do Ducto Granuloso & 12914,90 & $\pm 1378,19$ & 16693,57 & $\pm 4118,35$ & 12042,0 & $\pm 811,74$ \\
\hline Célula do Ducto Granuloso & 13088,56 & & 16819,5 & & 12176,5 & \\
\hline
\end{tabular}
desintoxicação alcóolica

( \pm ) desvio padrão 
$\left(D_{1}\right.$ e $\left.D_{2}\right)$ o raio foi calculado em $\mathrm{mm}$ pela seguinte relação geométrica:

$$
\mathbf{r}=\mathbf{D}_{1} \cdot \mathbf{D}_{2} / \mathbf{2}
$$

O volume absoluto dos núcleos das células do ducto granuloso, com formato elipsóide, foi calculado pela fórmula geométrica da elipse:

$$
\text { Vndg }=p / 6 . D_{1} \cdot D_{2} \text {. ÖD } . \text { ÖD }
$$

A sobrestimativa da densidade de volume do núcleo (Efeito Holmes) foi corrigida pela fórmula: $\mathrm{K}_{0}=1+$ (3t /2D), onde: $\mathrm{K}_{0}=$ fator de correção; $\mathrm{t}=$ espessura do corte $(6 \mathrm{~mm}) ; \mathrm{D}=$ diâmetro médio do núcleo.

Conhecendo-se o volume absoluto do núcleo e as densidades de volume do núcleo e citoplasma, calculou-se o volume absoluto do citoplasma por regra de três simples, e por somatória o volume absoluto celular.

O número total de células $(\mathrm{Ni})$ do ácino e do ducto granuloso foi calculado pela relação entre o volume absoluto de cada estrutura em $\mathrm{mm}^{3}$ (Vti), e o volume absoluto celular em $\mathrm{mm}^{3}(\mathrm{~V})$, de modo que: $\mathrm{Ni}=\mathrm{Vti}$ / V (Tabela 3) constataram uma redução significante na taxa de fluxo salivar das glândulas parótida e submandibular de alcoólatras e fumantes, havendo também uma redução na secreção de proteínas salivares em ambas as glândulas. Ratos submetidos a uma dieta líquida contendo $36 \%$ do total de calorias como etanol, por 90 dias, também apresentaram redução no fluxo salivar e diminuição de proteínas. As glândulas parótidas demonstraram expressiva degeneração de gordura e atrofia das células acinosas. Estes resultados indicam que principalmente o etanol e em menor extensão a nicotina causam severas alterações morfológicas e funcionais após consumo crônico.

Em 1990, Maier, et al. ${ }^{10}$, investigaram o efeito do consumo crônico de etanol (36\% do total de calorias como etanol, por 90 dias) na morfologia da glândula parótida de ratos. Investigações na microscopia de luz e eletrônica mostraram um notável acúmulo de gordura nos tecidos glandulares dos animais alcoolizados em relação aos ratos do grupo controle. Além das disposições de gordura nos tecidos intersticiais, gotas

TABELA 3- Número total de células acinares e do ducto granuloso dos Grupos Controle, Alcoolizado e Desintoxicado

\begin{tabular}{llll}
\hline Compartimento Glandular & CONTROLE & ALCOOLIZADO & DESINTOXICADO \\
\hline Ácino & 17795320 & 15346682 & 18096138 \\
Ducto Granuloso & 4937136 & 1987569 & 4167040 \\
\hline
\end{tabular}

\section{Análise estatística}

Os dados obtidos foram confrontados dois a dois, pela análise de variância (ANOVA), segundo indicações de Lison ${ }^{6}$ (1958), com P£0,05. No caso da densidade de volume, os testes estatísticos foram realizados após a transformação em arco-seno dos dados originais.

\section{RESULTADOS E DISCUSSÃO}

O presente estudo morfométrico demonstra que a ingestão de etanol a $20 \%$ promove alterações na glândula submandibular. A análise dessas alterações é complexa em virtude delas ocorrerem também sistemicamente, principalmente relacionadas às funções nervosas e endócrinas, segundo Kley, Teschke $^{7}$ (1985).

Estudos como o de Maier, Born, Mall ${ }^{9}$ (1988) verificaram os efeitos do consumo crônico de etanol e da nicotina sobre glândulas salivares humanas. Eles de gordura de vários tamanhos ocorreram na maioria das células acinosas. Investigações morfométricas adicionais revelaram uma diminuição no volume médio da célula acinosa $(-21,9 \%$ P $>0,001)$. Os achados posteriores refletiram uma atrofia do parênquima secretor o que parece ser responsável pela diminuição da secreção salivar após o consumo crônico de etanol.

De acordo com Lieber ${ }^{8}$ (1991), o álcool, por ser uma substância energética, promove a sensação de saciedade o que leva à inapetência em associação a distúrbios gastrointestinais que acarretam a má absorção de nutrientes, resultando, como conseqüência, em perda de peso, principalmente se ingerido cronicamente. Uma significante redução de peso corpóreo também foi observada por Dees, Skelley $^{5}$ (1990) no início da puberdade de fêmeas de rato após administração de álcool etílico.

No estudo de Banderas, et al. ${ }^{2}$ (1992) ratos Wistar de 2 meses de idade ingeriram 10\% de solução de etanol por 12 meses. Suas glândulas parótidas foram comparadas com um grupo controle em microscopia de luz. Eles apresentaram extensa transformação oncocítica ductal e acinosa; numerosas células atípicas 
mostraram anisocitose, poliploidismo e hipercromatismo, características não relatadas nos controles. Oncocitose e células acinosas atípicas são características relatadas em ratos Wistar de 2-3 anos (senil), o que leva os autores a concluírem que a ingestão crônica de álcool pode produzir características semelhantes àquelas observadas na glândula parótida de ratos Wistar "idosos".

No presente trabalho, o período experimental de 20 semanas pode ser considerado longo ao levarmos em conta que o rato é uma espécie animal com uma vida média presumidamente curta ao compará-lo à perspectiva de vida humana; justificando-se então, pouco mais de 3 meses ser tempo suficiente para que o experimento seja aceito como crônico.

Durante esse período houve uma considerável perda de massa corpórea dos animais alcoolizados antes do sacrifício, diferença confirmada ao analisarmos estatisticamente as massas dos animais (Tabela 1), corroborando com os achados de Lieber ${ }^{8}$ (1991). No entanto, após o período de desintoxicação, os animais apresentaram um ganho de massa corpórea, ao compararmos com suas massas um mês antes de serem submetidos à desintoxicação.

Semelhantemente às massas corpóreas, as massa glandulares dos grupos alcoolizado e desintoxicado foram estatisticamente menores em relação ao grupo controle. Essa perda de massa pode ser explicada pela redução do volume absoluto $\left(\mathrm{mm}^{3}\right)$ do ácino e do ducto granuloso (Tabela 2), porção secretora da glândula. A mesma estimativa para as outras estruturas glandulares não apresentaram diferenças estatisticamente significantes entre os grupos. Isto também se explica pela idéia de Lieber $^{8}$ (1991) pois, com a sensação de saciedade provocada pelo álcool, o animal tende a ingerir um menor volume de dieta e, assim, há um menor estímulo das glândulas salivares, esse desuso pode levar a uma atrofia glandular com uma diminuição do tamanho da glândula.

Como não encontramos diferença estatisticamente significante para o volume absoluto $\left(\mathrm{mm}^{3}\right)$ do núcleo e do citoplasma da célula acinosa e do ducto granuloso, pôde-se concluir, após quantificação do número total de células acinosas e células do ducto granuloso, que a redução da massa glandular ocorreu por uma redução no número total desses tipos celulares.

Ao compararmos o volume absoluto glandular do grupo alcoolizado com o grupo desintoxicado notamos um aumento após o período de desintoxicação, sendo esse aumento devido ao aumento de volume dos ácinos e ductos granulosos, sem alterações significativas para outras estruturas glandulares (Tabela 2).

A maioria dos volumes absolutos do núcleo e do citoplasma das células acinosas e das células do ducto granuloso não sofreu alterações significantes, com exceção do volume absoluto do núcleo da célula do ducto granuloso (grupo alcoolizado) que foi menor que o grupo controle (Tabela 2).

Em suma, podemos dizer que o álcool através do efeito sistêmico promove mudanças na saliva causando diminuição no fluxo salivar e modificações na sua consistência, tornando-a mais viscosa. Dessas mudanças advêm alterações nas glândulas salivares, consequiência direta ou indireta da ação do álcool. A glândula alterada gera mudanças morfológicas principalmente na sua porção secretora (ácinos e ductos granulosos) e essas, por sua vez, promovem alterações na produção e secreção salivar.

\section{ABSTRACT}

This work is a morphometric study of several parenquimatous structures of rats' submandibular gland which were submitted to experimental cronic alcoholism and others which were recovered after detoxication during 30 days. It was used 3 groups (5 rats in each group): Control, Alcoholic and Detoxicated. The fact of alcohol acts in body tissues, take us to believe that changes in the submandibular glands morphology of rats which were submitted to cronic alcoholism can happen. In fact, after alcoholisation and detoxication there is an occurence of significant statistically differences when we confront the 3 groups one another (two by two) in reference to the body weight of the animals $(\mathrm{g})$ and the submandibular gland weight $(\mathrm{mg})$. Usually, occurred a decrease in the alcoholic group and in the detoxicated group as well, towards the control group and a significant increase of the body and gland weight from the detoxicated group in relation to the alcoholic group. Regarding the total volume of the several gland structures evaluated, it was verified significant statistically differences in the acinar and granulous duct compartments, in which the alcoholic and the detoxicated groups presented a smaller total volume than the control group. About the other stereologic parameters evaluated, there was not significant statistically differences among the groups neither among the several gland structures evaluated.

UNITERMS：Alcoholism; Detoxication; Submandibular gland; Rats. 


\section{AGRADECIMENTOS}

À Tânia Mary Cestari, bióloga do Departamento de Ciências Biológicas-Histologia - FOB-USP, pelo processamento histológico.

Ao CNPq, processo n ${ }^{\circ} 112272 / 98-3$, pelo apoio financeiro.

\section{REFERÊNCIAS BIBLIOGRÁFICAS}

1- Aherne W. Methods of counting discrete tissue components in microscopical sections. J roy Micr Soc 1967; 87: 493-508.

2- Banderas JA. et al. Effects of cronic ethanol consumption on the rat parotid gland. Arch Oral Biol 1992 Jan; 37(1): 69-72.

3- Cagnon VM, Garcia PJ, Martinez FE, Martinez M, Padovani CR. Ultrastructural study of the ventral lobe of the prostate of rats submitted to experimental chronic alcoholism. Prostate 1993; 22(4):317-24.

4- Chalkley HW. A method for the quantitative morphologic analysis of tissue. J nat Cancer Invest 1943; 4: 47-53.

5- Dees WL, Skelley CW. Effects of ethanol during the onset of female puberty. Neuroendocrinology 1990 Jan; 51(1): 64-9.

6- Ferraz de Carvalho CA, Laurindo FR, Sesso A, Taga R. Morphometric studies on the development of acinar cells of the rat pancreas and parotid gland. Verh Anat Ges 1978; (72): 67781.

7- Kley HK, Teschke R. Alcohol and fertility: sex hormones. Z Hautkr 1985 Jul; 60(13): 1017-25.

8- Lieber CS. Hepatic, matabolic and toxic effects of ethanol. Alcohol Clin Exp Res 1991; 15(4): 573-92.

9- Maier H, Born IA, Mall G. Effect of cronic ethanol and nicotine consumption on the function and morphology of the salivary glands. Klin Wochenschr 1988; 66(sp. 11): 140-50.

10- Maier H. et al. Lipomatous atrophy of the parotid gland in chronic alcohol consumption. Laryngorhinootologie 1990 Nov; 69(11): 600-4.

11- Otto MJ, Löw O, Schneider A. The nominal section thicknessimportance of their correction for morphometry. Exp Path 1991; 42(3): $129-36$

12- Pardini LC, Taga R. Evaluation on the density of mouse submandibular gland by the method scherle. Rev Fac Odontol Ribeirão Preto 1986 jul./dez.; 23(2): 205-7.

13- Scherle W. A simple method for volumetry of organs in quantitative stereology. Mikroskopie 1970 Jun; 26(1): 57-60.

14- Scott J, Berry M, Woods K. Effects of acute ethanol administration on stimulated parotid secretion in the rat. Alcohol Clin Exp Res 1989 Aug; 13(4): 560-3.
15- Scott J, Burns J, Flower A. Histological analysis of parotid and submandibular glands in chronic alcohol abuse: a necropsy study. J Clin Pathol 1988 Aug; 41(8): 837-40.

16- Stipp ACM. Estudo morfológico e morfométrico da glândula submandibular do hamster. Bauru; 1997. [Tese de Livre Docência - Faculdade de Odontologia de Bauru da USP].

17- Tirapelli LF. Alterações morfológicas nas glândulas submandibulares de ratos (Rattus norvergicus) submetidos ao alcoolismo crônico experimental. Botucatu ; 1998. [Tese de Doutorado - Instituto de Biociências de Botucatu da UNESP].

18- Weibel ER, Kistler GS, Scherle WF. Practical stereological methods for morphometric cytology. J Cell Biol 1996 July; 30(1): 23-38.

Correspondência:

Simone Eloiza Sita Faustino

R. Expedicionários do Brasil, 3399. Vila Yamada.

CEP 14802-150. Araraquara-SP

Fone: (16) 3331-4335 / 3335-9726

E-mail: sesfaustino@hotmail.com

Antonio Carlos Marconi Stipp

Al. Octávio Pinheiro Brisola, 9-75. Vila Universitária. CEP 17012-901. Bauru-SP.

E-mail: acmstipp@fob.usp.br

Fone: (14) 235-8259 